\title{
Childcare Experiences of Teachers Handling Infants and Toddlers with Disabilities
}

\author{
Hyun-Sook Lee ${ }^{1}$, Mi-Na Lee ${ }^{2}$ \\ ${ }^{1}$ The Doctor's Course, Department of Human Service Education, Kwangshin University, South Korea, \\ gogo1000@hanmail.net \\ ${ }^{2}$ Professor, Welfare Counseling Convergence Department, Kwangshin University, South Korea, \\ Imn4780@naver.com
}

Corresponding author: Mi-Na Lee

\begin{abstract}
This paper presents a field study on the childcare experiences of childcare teachers for children with disabilities. An interview was conducted to find out how to improve the quality of childcare for children with disabilities by examining the experiences of childcare teachers. The participants were six childcare teachers working at a daycare center specializing in children with disabilities. The field experience questions of this study include work motives, job satisfaction, difficulties at work, childcare teacher qualification system, and improvement points for integrated childcare for disabled children. As a result of the study, it was found that the difficulties experienced by nursery teachers for infants and toddlers with disabilities include supporting integrated education, human relationships, and administrative concerns. Therefore, the difficulties and rewards experienced by childcare teachers with children having disabilities are described from the point of view of the education subject, and various meanings are presented to them by in-depth interpretation from the educational point of view. This study is intended to provide basic data for teacher qualification and evaluation for the qualitative development of childcare after the introduction of the childcare teacher system for children with disabilities.
\end{abstract}

Keywords: Children with Disabilities, Childcare Teacher Experience, Teacher Expertise, Roles and Qualifications, Integrated Childcare with Disabilities

\section{Introduction}

Recently, the problem of low birth rate is one of the biggest issues in Korea. As the total fertility rate in 2020 recently posted on the National Statistical Portal (KOSIS) stood at 0.84, the lowest in OECD countries and the world, the country has been making efforts to expand childcare facilities that can help parents overcome low birth rates. Among them, childcare for infants with disabilities should help the growth and development of infants with disabilities and provide childcare services that meet the needs of families with disabilities. The role and quality of teachers in providing quality childcare services to infants and their families is an important factor in determining the quality of childcare.

Recently, Due to the growing interest in childcare and education of infants with disabilities in daycare centers, the quality and attitude of teachers towards children with disabilities are becoming increasingly important. Unlike other professions, teachers teach humans and are jobs that only people with special qualities and sense of mission can do[1]. In the past, it was sufficient for teachers to deliver

Received: August 30, 2021; 1st Review Result: October 15, 2021; 2nd Review Result: November 30, 2021 Accepted: December 31, 2021 
and acquire knowledge and functions to students, but current teachers must continue to be professional and play a role as educational experts so that students can grow and develop as a whole. There are various factors that affect the quality of education, such as curriculum, teaching method, educational environment, and teachers, but most of all, teachers are the ones who organize and integrate them at the educational site[2]. The scope of childcare should be both educational and protective for infants, which is a critical time for growth potential and development, so disabled infant teachers must play a pivotal role in the quality of childcare by properly helping infants grow and develop. In particular, the quality of childcare teachers for infants with disabilities is more important than anything else because they establish primary relationships with infants with disabilities and provide the best qualitative childcare services based on technology, knowledge and resources[1]. Reflecting this, Korea designates a daycare center specializing in childcare for disabled infants and requires childcare teachers who are qualified as teachers for disabled infants. Many facilities, such as the environment in which each developmental characteristic is suitable for high-quality infant care and child care programs are important and disabled infant teachers with excellent quality should implement and utilize them[3][4]. Therefore, it has been argued that childcare teachers for infants with disabilities should provide systematic education for infants with disabilities and help them achieve their full potential[5]. In this study, the researchers aim to start discussions to improve the quality of childcare for disabled children by looking into the child care experience of the teachers who are currently responsible for the disabled. Therefore, it is hoped that the results of this study will provide basic data to evaluate the qualification system for the qualitative development of childcare for disabled children after the introduction of the childcare teacher system for infants with disabilities.

Research problem

1. Why did you work as a childcare teacher for infants with disabilities?.

2. What is the satisfaction of working as a childcare teacher for infants with disabilities?.

3. What was difficult about working as a childcare teacher for infants with disabilities?.

4. What do you think is the improvement of the current childcare system for infants with disabilities and integrated childcare?

\section{Theoretical Background}

\subsection{Nursery and Day Care Teachers Specializing in Infants with Disabilities}

\subsubsection{Nursery Specializing in Infants with Disabilities}

Childcare centers specializing in infants with disabilities shall be facilities designated by the Mayor, the Governor, and the head of the facilities. In other words, it refers to a special educational institution for disabled infants or children up to the age of 12 where childcare teachers, special teachers, and therapists can join in daycare centers and provide education and treatment for disabled infants and disabled children. Child care centers specializing in disabled children have been designated as the primary business goal since 1996 to address the unique rehabilitation needs of disabled children and the financial burden of parents. Since 1997, they have been designated as disabled childcare centers to present facility standards and operating standards. Before 2012, the Korean childcare system stipulated that specialized childcare facilities for children with disabilities are equipped with facilities under the Enforcement Rules of the Infant and Child Care Act and provided childcare for more than 18 disabled children. Since 2012, Article 32 of the Disabled Children's Welfare Support Act has been amended to a daycare center for children with disabilities or more, and the name has also been changed to a daycare center specializing in disabled children.

In addition, the head of a daycare center specializing in children with disabilities (in a state where it 
is impossible to go to school) has exceptions for children who are suspended or exempted from school under the Enforcement Decree of the Act on Special Education for Persons with Disabilities (Article 27 of the Infant Care Act). In other words, it is a special educational institution for infants with disabilities and children with disabilities up to the age of 12 , where childcare teachers, special teachers, and therapists can provide education and treatment for infants with disabilities and children at daycare centers.

\subsubsection{Child Care Teacher for Infants with Disabilities}

With the implementation of the Disabled Child Welfare Support Act 2012, a teacher will be recognized as a childcare teacher for disabled children only if they completed 80 hours of vocational or online education or 40 hours of special education (Korea Childcare Promotion Agency, 2017). However, since March 1, 2015, it has banned the recognition of qualifications through online and job education and has deployed special teachers and childcare teachers who are qualified for infants with disabilities.

The qualification of a childcare teacher for infants with disabilities under Article 21(3) of the Infant Care Act is a person who has a second or higher certificate and has completed special education or rehabilitation-related subjects and credits prescribed by the Ministry of Health and Welfare, or has been recognized under Article 7 of the Higher Education Act. Article 32 of the Disabled Child Welfare Support Act requires daycare centers for infants with disabilities who qualify as Article 5 (1) of the Enforcement Decree to gradually expand their child care teachers to 5, 4, and 3, depending on the age of disabled infants every year from March 1, 2016 (Ministry of Health and Welfare, 2018). The requirements for childcare teachers for infants with disabilities are as shown in [Table 1].

[Table 1] Requirements for Child Care Teachers for Infants with Disabilities

\begin{tabular}{|c|c|}
\hline Sortation & Qualification requirements \\
\hline $\begin{array}{l}\text { Qualification and } \\
\text { assignment of } \\
\text { childcare teachers } \\
\text { for infants with } \\
\text { disabilities } \\
\text { (Enforcement } \\
\text { Decree of the } \\
\text { Welfare Support } \\
\text { Act for Children } \\
\text { with Disabilities) }\end{array}$ & $\begin{array}{l}\text { Article } 5 \text { (Qualification of childcare teachers for infants with disabilities) } \\
\text { The criteria for qualification of childcare teachers for infants with disabilities under Article } 22 \text { (3) shall be } \\
\text { those who are qualified as follows: } \\
\text { A. A person who has a certificate of Grade } 2 \text { or higher as a child care teacher under Article } 21 \text { (3) of the } \\
\text { Infant Care Act; } \\
\text { B. A person who has completed special education or rehabilitation-related curriculum credits prescribed } \\
\text { by the Ministry of Health and Welfare at a school under Article } 2 \text { of the Higher Education Act or has been } \\
\text { recognized under Article } 7 \text { of the Act on Credit Recognition, etc. } \\
\text { The arrangements under paragraphs (1) and (2) shall be carried out sequentially in accordance with the } \\
\text { following standards: } \\
\text { 1. Infants with disabilities aged five years or older who have not attended school: From March } 1,2016 \\
\text { 2. Disability infants aged four from March 1, } 2017 \\
\text { 3. Disabled infants at the age of three from March } 1,2018\end{array}$ \\
\hline
\end{tabular}

The basic curriculum and credits related to special education and rehabilitation to be completed in order to obtain qualifications for childcare teachers for infants with disabilities are as shown in [Table $2]$.

[Table 2] Basic Subjects and Credits related to Special Education and Rehabilitation

\begin{tabular}{|c|l|}
\hline Sortation & Basic Subjects \\
\hline $\begin{array}{c}\text { August } 2012 \\
\text { A person who } \\
\text { transferred or entered } \\
\text { the school four days } \\
\text { ago (at least 16 score) }\end{array}$ & $\begin{array}{l}\text { Sensory education, individualized education plan, educational introduction, child care practice, child } \\
\text { development, language development, language therapy introduction, methodology for infant and } \\
\text { child education, impaired child education, mental retardation education, disabled child education, } \\
\text { specialized child counseling. }\end{array}$ \\
\hline August 2012 & Education for children with learning disabilities \\
\hline
\end{tabular}


Eight score (24) or more for those who transferred or entered the school after five days.
Sensory education, individualized education plan, early intervention in developmental children, language therapy, visual education, disabled child care practice, disabled infant teaching methodology, disabled child education, mental retardation education, autism education, special child counseling and family support, special education

Compared to the basic curriculum related to special education and rehabilitation before August 4, 2012, the introduction of education, child care practice, child development theory, and practical education methodology are excluded from the curriculum after August 5, 2012. In addition, early intervention in developmental retardation infants, speech development disorders, disabled child care theory, disabled child care practice, and disabled infant teaching methodology are added. This was changed to a specialized basic curriculum for infants with disabilities after August 5, 2012, compared to the basic curriculum related to special education and rehabilitation before August 4, 2012.

\subsubsection{Professionalism of Infant Care Teachers with Disabilities}

The expertise required as a child care teacher is the knowledge or skills that a child care teacher typically has to provide quality child care services to infants and children, and their special role as a child care teacher is important[6][7]. Studies on the professionalism of general childcare teachers show that infants are susceptible to surrounding influences, especially from child care teachers who are human environments, and that child care teachers who have professional abilities are more important than any other environment[8]. The expertise required as a special infant teacher, as well as the expertise required as a general childcare teacher include the understanding of disabled infants, the development and application of appropriate teaching methods for disabled infants, and the ability to respond to problem behavior[9][10].

In accordance with a study by Saracho \& Spodeck[7], the criteria for the professionalism of childcare teachers for infants with disabilities are divided[11]. First, it includes expertise and skills for infants with disabilities and skills to select and guide proper education contents for infants with disabilities, continuous information acquisition skills, and information provision skills through parent counseling. Second, it is the responsibility and obligation to promote a sense of mission, awareness, and healthy growth and development through service for infants with disabilities. Third, it means that child care teachers for infants with disabilities should be able to voluntarily select educational goals and methods that are appropriate by faith and philosophy in providing integrated child care services and practice them with responsibility. Fourth, it means that child care teachers for infants with disabilities recognize the practice as educators and are faithful to their role according to their beliefs, including personally respecting infants with disabilities, understanding, accepting and positively guiding them in various positions.

\subsubsection{The Role and Qualities of Child Care Teachers for Disabled Infants with Disabilities}

Child care teachers present educational experiences so that infants can grow and develop safely and develop abilities that meet the appropriate level of infants and toddlers. It also enables all infants to grow healthy and safely[12]. Child care teachers require a variety of roles away from protection, quality of child care is deeply related to child care teachers, and the role of professional and quality factors of child care is important[13]. Human resources are important to provide qualitative services to all infants and children who need childcare. Therefore, since the quality-driven role of childcare is a child care teacher, the correct perception of the role should be made.

The role of child care teachers for infants with disabilities should be to provide individualized education based on the individual needs of infants with disabilities, provide appropriate teaching methods and various materials for disability integrated classes, plan for appropriate intervention in the 
behavior of infants with disabilities[14]. The role of child care teachers for infants with disabilities is also defined as follows[15]. First, childcare teachers for infants with disabilities should have a basic knowledge of the development of infants with disabilities. Second, develop an individualized education plan. Third, it promotes active participation of infants with disabilities and leads them to members of disability integration classes. Fourth, it promotes active interaction between infants with disabilities and infants with general disabilities and allows them to deal with them without prejudice and discrimination against infants with general disabilities. Fifth, it serves to establish continuous cooperation with general childcare teachers for infants with disabilities and to train general childcare teachers with appropriate knowledge and methods for integrated childcare and infants with disabilities.

In order to play the role of a child care teacher for such infants with disabilities, the quality of a child care teacher is important. This is because even if the physical environment for integrated child care is appropriately configured, the quality of integrated child care may vary depending on the quality of childcare teachers for infants with disabilities. Therefore, it is said that childcare teachers for infants with disabilities need to make efforts for self-development in order to perform a variety of tasks[16].

Child care teachers must have personal and professional qualities. Individual qualities are said to be healthy and emotional stability, a mind that likes and respects all infants, a position that strives for smooth human relationships and self-development[17]. In addition, the professional qualifications of childcare teachers are systemized curriculum theory and knowledge for infants and children, and skills that can be used in interaction with infants and children, linking self-development, family support, and community. In addition to the basic qualities of childcare teachers, childcare teachers for infants with disabilities include concepts of development and learning, early intervention suitable for development, cooperation with experts, diagnosis and evaluation, and spirit and attitude as experts[18][19]. In addition to personal qualifications, the quality of childcare teachers for infants with disabilities can be considered as general knowledge of integrated child care, expertise in child education, role performance, teaching and attitude toward culture.

\subsubsection{Field Experience of Childcare Teachers for Infants with Disabilities}

Becoming a childcare teacher for infants with disabilities creates new human relationships and gives them new opportunities to challenge them. From the perspective that past experiences affect current experiences, the experience of childcare teachers for infants with disabilities affects the overall integrated child care. Therefore, when faced with reality, childcare teachers for infants with disabilities face many difficulties and stresses in their working environment and professionalism. Since understanding the experience of childcare teachers for infants with disabilities is important for the improvement of disability integration, prior studies have mainly been conducted on the overall teaching experience of teachers with disabilities, special teachers, and collaboration with general teachers in disability integration classes.

In the study of children with disabilities, we wanted to explore what experiences special teachers have in the process of growth and what factors are associated with growth to good special teachers[20] through an analytical phenomenological approach. Studies have shown that the difficulty of teaching is inferred from disabled students, but the power to continue as a special teacher is also from disabled students. It was shown that special teachers started, grew related to professionalism, grew through selfdevelopment, and grew internally, and the meaning of special teachers was positive, resilient thinking, communication and relationship, and a sense of mission as special education experts. In particular, efforts to secure professionalism have served as an opportunity to grow into better teachers when recognized by parents, fellow teachers, and managers. Through various teaching experiences, they experienced the process of rediscovering the fundamental meaning and value of the job as a teacher.

It has been shown that efforts have been made to enhance professionalism in a variety of ways. 
There are studies on awareness and curriculum modification efforts for kindergarten teachers who have experienced disability integration. It sought to explore practical methods and strategies and find out the perception and direction of integrated education through the experience and efforts of direct education modifications experienced in implementing integrated disability education[21]. According to the study, they expressed their vague and fearful feelings about disability integration in the beginning and had difficulties in attitude, method, and technology, but through various experiences, they gained positive awareness of disability integration through successful experience, type and extent of disability infants, and accumulated knowledge.

It was studied to find out the job experience of special infant teachers in public kindergartens[22]. Heavy work, the center of hard human relationships, other people's perception of infant special teachers, the value of infant special teachers, conflicting curriculum, doubts about disability integration, and anxiety about becoming an old teacher were among the concerns of special infant teachers. It was also shown to have experiences such as understanding others, acting as a medium for communication, coordinating opinions in various ways, seeking advice, improved human relations skills, efficient work processing skills, love for teachers and disabled infants, and recognition by parents and managers.

One research presented a case study on the difficulties and rewards of teaching life for special infant teachers[23]. Through in-depth interviews in the study, it was studied how special infant teachers led their teaching lives and how they are living in.

\section{Research Method}

\subsection{Research Subject}

\subsubsection{Research Participants}

The participants in this study are six child care teachers working at a daycare center specializing in disabled children. After explaining the purpose of the study and obtaining consent from six teachers who formed rapport among teachers with more than three years of experience, they are selected as participants in the study. shown in [Table 3]. This study conducted a qualitative research method targeting 6 participants.

[Table 3] Basic Information of Study-participating Day Care Teachers

\begin{tabular}{cccccccc}
\hline Num & Teacher & Age & Class & Sex & Married or not & Time schedule & Job experience \\
\hline 1 & A & 36 & $\begin{array}{c}\text { 3years old } \\
\text { classroom Nuri }\end{array}$ & Female & Married & full time & 11years \\
\hline 2 & B & 47 & $\begin{array}{c}\text { 3years old } \\
\text { classroom Nuri }\end{array}$ & Female & Married & full time & $\begin{array}{c}5 \text { years } \\
7 \text { months }\end{array}$ \\
\hline 3 & C & 48 & After school & Female & Married & full time & $\begin{array}{c}10 \text { years } \\
6 \text { months }\end{array}$ \\
\hline 4 & D & 40 & After school & Female & Not married & full time & $\begin{array}{c}14 \text { years } \\
6 \text { months }\end{array}$ \\
\hline 5 & E & 52 & $\begin{array}{c}\text { 6years old full } \\
\text { time classroom }\end{array}$ & Female & Married & full time & $\begin{array}{c}5 \text { years } \\
6 \text { months }\end{array}$ \\
\hline 6 & F & 26 & $\begin{array}{c}5 y \text { years old } \\
\text { classroomNuri }\end{array}$ & Female & Not married & full time & $\begin{array}{c}3 \text { years } \\
1 \text { months }\end{array}$ \\
\hline
\end{tabular}

\subsection{Characteristics of Study Participants}

\subsubsection{Teacher A}

As a mother of two seven-year-old and five-year-old children, she graduated from the Department of 
Speech Therapy and worked as a language therapist at a special school. It is said that the teacher's children are particularly interested in the children because they are in infancy She is kind to her children and parents as well, and she gets along with her colleagues. She is also qualified to be an infant special teacher at a daycare center specializing in disabled children.

\subsubsection{Teacher B}

The teacher has a warm heart. He takes a lot of interests on children. She interacts well with children and has interested conversations with his parents. She went to college late and got a job at a daycare center specializing in disabled children. There are many preconceptions that disabled infants are different from ordinary infants, but they are slow to develop, and teachers should try to inform parents and people around them that they should be more inrerested on their children with special needs.

\subsubsection{Teacher $\mathrm{C}$}

The teacher majored in early childhood education and worked as a day care teacher at a general daycare center. After taking a leave of absence due to child rearing, She got a job at a daycare center specializing in children with disabilities because She was interested in disabled children due to her acquaintance's recommendation and previous experience in autistic child rearing. It is said that parents feel rewarded when they thank their parents when they have a consensus on parents and infants and show improvements such as modifying their behavior through family connections.

\subsubsection{Teacher D}

The teacher said that after graduating from the Department of Early Childhood Education, he worked as a teacher at a daycare center for children with disabilities, and that it was attractive that the ratio of teachers to children with disabilities was 1:3. After graduating from a daycare center, a disabled child entered an elementary school and went to a special class or special school is in charge of after-school activities. As a principal teacher, he manages the documents of daycare centers or the makeup of faculty members. Understanding the specificities of disabled children and finding proper education for children feel rewarding when the effects of education are shown in children, but is difficult to cope with children's unexpected or aggressive behavior when they have been trained hard.

\subsubsection{Teacher $\mathbf{E}$}

The teacher was employed at a daycare center specializing in disabled children and is very satisfied because she became interested in childcare after entering a university where she could qualify as a child care teacher. She tried to understand the negative view of disabled children in a positive way.

\subsubsection{Teacher $\mathbf{F}$}

The teacher worked at a social welfare company daycare center for three years. Her mother works at daycare centers and kindergartens, and she has always seen her work happily ever since she was young, so it was her dream to become an infant teacher. She is currently working at a daycare center specializing in disabled children at the recommendation of a friend who is a special teacher for infants, and She feels rewarded when disabled infants follow the homeroom teacher and parents express their gratitude.

\subsection{Ethical Considerations for Study Participants}

This study investigates the subjects' occupational identity through in-depth interviews. The researcher fully explained to the study participants the subject, purpose and method of the study prior to the interview, confirming their willingness to participate in the study and seeking consent. They were 
informed that the content of the interview was confidential and would not be used for any other purpose other than the study, indicating that the interview would be recorded and discarded at the end of the study. A study participation agreement containing these information was prepared and signed prior to the interview.

\subsection{Research Tools}

In this study, the researchers prepared a list of interviews with semi-structuring to lead the story of the study participants in depth and breadth. Interview questions were compiled based on prior research on transfer in childcare facilities[24]. A mixture of semi-structured interviews and open questions about the personal background of a nursery teacher's occupational choice, etc. was used to obtain information such as satisfaction and difficulty as a disabled infant teacher[23][25]. After preparing a list of interview questions, the the supervisors reviewed the questions, and the researchers modified them to reconstruct the questions. In addition, a list of interview questions was reviewed for one day care teacher with more than five years of experience at a daycare center specializing in disabled children who did not participate in the study. The interview questionnaires are as follows.

\subsubsection{Questions}

Question 1. The background of a former or currently working disabled infant teacher.

1-1 What experiences did you have before working at a daycare center for disabled children?

1-2 Why did you choose the job as a day care teacher and what was your main job?

1-3 The reason why I quit my previous work institution and got a job at a daycare center specializing in children with disabilities. What is it?

1-4 Is there any particular reason you're working at a daycare center specializing in disabled children?

Question 2. Experience as a child care teacher for infants with disabilities

2. What do you think about the working environment of a daycare center specializing in disabled children?

2-1. Age of homeroom class, special education work, non-special education work, parent atmosphere

2-2. Do you have any satisfaction as a child care teacher with disabilities?

2-3. What are some of the difficulties you have experienced as a child care teacher with disabilities?

Question 3. Qualification system for infants with disabilities and improvements in integrated child care.

3-1. What is the improvement in the qualification and system of childcare teachers for infants with disabilities?

3-2. What are some improvements to integrated childcare in disabled care centers?

\section{Results}

\subsection{Personal Background of Child Care Teachers with Disabilities}

\subsubsection{What Experiences Did You Have Before Working at a Daycare Center for Disabled Children?}

When asked about their experience before working at a day care center for disabled children, many said that other teachers, except for teacher F, worked in social welfare such as general daycare centers, special daycare centers, and hospitals, naturally became interested in disabled children.

I worked at a special school and as a teacher at a daycare center dedicated to children with disabilities. (Teacher A) 
I worked as an ophthalmologist(Teacher B)

I worked as a nursery teacher at a general daycare center(Teacher C)

I worked as a child care teacher at a private daycare center(Teacher D)

I sold clothes at the department store(Teacher E)

I worked at a general social welfare company daycare center for about two years and six months(Teacher F)

\subsubsection{Why Did You Choose the Job as a Day Care Teacher and What was Your Main Job?}

When asked about the special reason for working at a daycare center specializing in disabled children, They answered because of the recommendation of their neighbors, and that they were attracted to having a certificate because there were people with disabilities around them.

I worked because people around me introduced me to the job of childcare teacher for infants with disabilities and encouraged me to try it(Teacher A)

I became interested in disabled person because there was someone with a disability in the family history so I worked at a daycare center specializing in disabled children(Teacher B)

When I first worked at a daycare center, I had experience with autistic infants, so I naturally became interested in infants with disabilities and worked at a daycare center specializing in disabled children(Teacher C)

\subsection{Experience as a Day Care Teacher for Infants with Disabilities}

\subsubsection{What was the Reacher's Age, Special Education Work, Non-special Education Work, and Parental Atmosphere?}

When asked what they thought about the working environment of daycare centers for disabled children, they found that they were generally satisfied with the working environment, positive about their work, and felt good relationship with their parents.

My work and working environment are good and my relationship with my parents is good(Teacher A)

I am currently in charge of childcare and education for children with disabilities who are 8 to 13 years of age. It can be said that appropriate childcare and education are provided in connection with the family according to the parents' needs(Teacher $\mathrm{C}$ ).

I think it's positive that we can provide proper services to infants in education and childcare because it's an institution that specializes in infants with disabilities, not in integration or mixed classes for disabled children(Teacher F)

\subsubsection{Do You Have Any Satisfaction as a Child Care Teacher with Disabilities?}

When asked if they had any satisfaction as teachers for infants with disabilities, both respondents responded that they were satisfied with the development and positive interaction of infants.

I feel satisfied with my work when the end of the semester end of the semester for infants with disabilities(Teacher B)

I felt satisfied when the effects of education were shown in children while understanding the specificities of children with disabilities and finding proper education for children(Teacher D)

Although I have a disability, I recognize my homeroom teacher and follow him well, and I feel satisfied when my parents express their gratitude for him(Teacher E)

\subsubsection{What are Some of the Difficulties You Have Experienced as a Child Care Teacher with Disabilities?}

When asked about the difficulties experienced as a teacher of infants with disabilities, there were 
various responses, including social views on child abuse, difficulties in guiding children, relationships with parents, and inappropriate views on disabled children.

I feel heavy on the inappropriate perspectives and perceptions of people around me regarding child abuse, which has recently emerged(Teacher A)

Children with disabilities in multicultural families have difficulty communicating with their parents(Teacher B)

When you feel a biased view of outdoor activities, it's very embarrassing when children act out of the blue, and it's very difficult to deal with children's sudden violent behavior for no reason(Teacher C)

\subsection{Educational Qualification System for Infants with Disabilities and Improvement of Integrated Childcare for Disabilities}

\subsubsection{What is the Improvement in the Qualification and System of Childcare Teachers for Infants with Disabilities?}

Regarding the current improvement in the qualification and system of infant care teachers with disabilities, there was an answer that it would be good to improve treatment proportional to work and change the perception of infant care teachers with disabilities.

It's a pity that there seems to be a lot of lack of understanding and expertise about disabled children. I hope that there will be more measurements and support for disabled infant teachers on a regular basis(Teacher D)

I hope there will be higher pay for infant care teachers with disabilities and better treatment than now(Teacher E)

We need to improve the treatment of the poor environment compared to the given workspace(Teacher F)

\subsubsection{What are Some Improvements to Integrated Childcare in Disabled Care Centers?}

As for the improvement in integrated childcare at daycare centers for disabled children, there were answers to the improvement of the perception of non-disabled parents, the view of integrated childcare, and the deployment of auxiliary personnel.

I believe that appropriate integration is needed according to the type of disability and the deployment of auxiliary personnel according to the number of children is urgent(Teacher $\mathrm{C}$ )

I believe that the quality of education is degraded due to long-term childcare, and that the deployment of supplementary personnel and appropriate personnel is necessary for smooth integration(Teacher D)

The general public, especially in the same day care center, requires better awareness and warm views from parents of non-disabled children(Teacher E)

\section{Conclusion}

The work experience of a childcare teacher for children with disabilities requires an understanding of the childcare teachers themselves and a sufficient awareness of children with disabilities. Furthermore, research on the recent experience of childcare teachers for infants with disabilities after the eligibility system for childcare teachers for infants with disabilities should be continued.

Nursery teachers who teach children with disabilities are busy taking care of children with disabilities. This results in teachers experiencing psychological burnout and stress on the job. The difficulties experienced by childcare teachers for infants with disabilities showed that they experienced difficulties in supporting integrated education, difficulties in human relations, and administrative difficulties, and felt rewarded by disabled infants, parents, and fellow teachers. Therefore, it was described as an educational entity's perspective on the difficulties and rewards experienced by infant care teachers with 
disabilities, and presented various meanings to infant care teachers with disabilities through in-depth interpretation from an educational perspective.

A childcare teacher who works at a daycare center specializing in children with disabilities needs to understand children with disabilities and their families, and when they think positively about the development of children with disabilities and are satisfied with their work, they can establish a good relationship with their parents. You can make it. There were negative perceptions of disabled children and having communication with parents. All six teachers who responded to the meeting mentioned improvements in the system and changes in treatment and negative perceptions. It is believed that disabled infant care teachers will be able to provide high-quality services to disabled infants in a happier environment. Therefore, it is believed that through this study, a more systematic teacher education program will be needed to improve awareness of childcare for infants with disabilities and to develop professionalism for high-quality level of childcare teachers.

The limitations of this study and suggestions for follow-up studies are as follows. First, there is a limit to generalizing the results of the study because it was conducted for teachers of daycare centers exclusively for the disabled in a specific area. Therefore, it is necessary to conduct follow-up studies in several regions. Second, there is a limit to the study with only self-report data on the stress experience in relationships with infants and toddlers in daycare centers for the disabled. There is a need to review more diverse study participants.

\section{References}

[1] G. H. Kim, Factors and development plan of the integrated education environment perceived by teachers who changed from elementary school general teachers to special education teachers,, Graduate School of Education, Daegu Graduate School of Education, Master's thesis, pp.8-14, (2017)

[2] C. S. Ahn, M. O. Shim, Elementary school teachers' perception of conflict in the teaching profession, Chuncheon National University of Education, Elementary Education Institute, pp.183-223, (2003)

[3] S. H. Ahn, J. E. Kim, A Depth Interview on Qualification, Role, and Professionalism of Infant/Toddler Teachers, Family and Environment Research, (2010), Vol.48, No.3, pp.87-97, UCI: G704-000012.2010.48.3.009

[4] H. Y. Sin, The effect of job stress and sense of efficacy on the quality of teacher's behavior in daycare centers, Yonsei University graduate school, Doctoral dissertation, pp.9-12, (2004)

[5] M. K. Yoon, A study on the restructuring of the curriculum of a teacher training institution to strengthen the core competency of special education teachers, Dankook University, Ph D thesis, pp.10-13, (2014)

[6] J. G. Jo, Study on Needs for Special Education Related Services and Child-Care of Parents of Young Children with Disabilities in Urban and Rural Area, The Journal of the Korean Association on Developmental Disabilities, (2012), Vol.16, No.1, pp.49-73, UCI: G704-SER000009845.2012.16.1.004

[7] O. N. Saracho, B. Spodeck, Professionalism and the Preparation of Early Childhood Education Practitioners, Early Child Development and Care, (1993), Vol.89, pp.1-17.

[8] J. H. Myung, The relationship between social support, job stress, and professional perception of childcare teachers, Sookmyung Women's University Graduate School of Education, Master's Thesis, pp.8-17, (2006)

[9] S. O. Yoo, Early childhood special education theory, Hakjisa, pp.35-48, (2005)

[10] G. E. Joh, A study on job stress and coping behavior of special school teachers, Kyonggi University Graduate School of Education, Master's Thesis, pp.12-20, (2003)

[11] J. H. Lee, A Study on Professional Perception and Job Stress of Nursery School Teachers for Disabled ChildrenFocused on Daejeon Metropolitan City, Yeungnam University Graduate School of Public Administration, Master's Thesis, pp.9-16, (2010) 
[12] Y. S. Kim, J. Y. Lee, Y. S. Song, Y. S. Kim, Nursery Teacher Theory, Park Young Story, (2014)

[13] G. E. Kim, Difficulties and demands of high-skilled teachers for their jobs, Pai Chai University Graduate School, Master's Thesis, pp.7-16, (2012)

[14] M. Wood, Whose Job is it Anyway? Educational Roles in Inclusion, Exceptional Children, (1998), Vol.64, No.2, pp.181-195, DOI: https://doi.org/10.1177/001440299806400203

[15] S. Y. Kim, H. O. Park, I. S. Choi, N. R. Park, B. S. Park, J. S. Kim, A Study on Support Measures for Expanding Integrated Kindergarten Education, National Institute of Special Education, pp.37-51, (2021)

[16] H. K. Kang, A study on the effect of childcare teacher job stress on job satisfaction, Ewha Womans University Graduate School of Social Welfare, Master's Thesis, pp.10-15, (2002)

[17] G. M. Jang, The relationship between the personal qualities of childcare teachers and the attachment of infants and toddlers, Graduate School of Counseling, Pyeongtaek University, Master's Thesis, pp.10-16, (2008)

[18] B. S. Seo, Development of an evaluation scale for integrated kindergarten classes, Pusan National University graduate school, Doctoral Thesis, pp.12-15, (2013)

[19] S. N. Kim, A survey of managers' expectations regarding the qualifications of early childhood special education teachers, Gongju University Special Graduate School, Master's Thesis, pp.9-14, (2003)

[20] J. B. Park Qualitative Inquiry about Culture teaching profession on special education teachers in special school, Journal of Special Education, (2005), Vol.12, No.2, pp.161-176, UCI: G704-001542.2005.12.2.012

[21] G. H. Back, Awareness of kindergarten teachers who experienced inclusive education for children with disabilities and efforts to revise the curriculum, Ewha Womans University Graduate School of Education, Master's Thesis, pp.8$15,(2011)$

[22] G. M. Kim, G. S. Jung, J. A. Noh, A Qualitative Study on the Work Experiences of Early Childhood Special Education Teachers at Public Kindergartens, Korean Journal of Early Childhood Special Education, (2013), Vol.13, No.3, pp.130, UCI: G704-001667.2013.13.3.002

[23] C. H. Lee, A case study on the difficulties and rewards of teaching life of special education teachers for early childhood, Chonnam National University Graduate School, Master's Thesis, pp.12-19, (2015)

[24] Y. C. Kim, Qualitative Research Methodology, Moonumsa, pp.40-53, (2006)

[25] H. S. Lim, A Narrative Exploration on the Process of Becoming a Nursery Teacher: Focusing on the Nursery Teacher Education Center, Kyonggi University, Doctoral thesis, pp.12-20, (2012) 